Modern Physics Letters A, Vol. 12, No. 30 (1997) 2317

(C) World Scientific Publishing Company

\title{
ERRATUM
}

\section{INFRARED FINITE CHARGE PROPAGATION}

\author{
[Mod. Phys. Lett. A, Vol. 12, No. 25 (1997) 1815-1821] \\ E. Bagan, B. Fiol, M. Lavelle and D. McMullan
}

On p. 1816, Eq. (2) was misprinted. It should read:

$$
\gamma^{-2} \partial_{1} A_{1}+\partial_{2} A_{2}+\partial_{3} A_{3}+v^{1}\left[\partial_{0} A_{1}-\partial_{1} A_{0}\right]=0,
$$

